Article

\title{
Salviolone from Salvia miltiorrhiza Roots Impairs Cell Cycle Progression, Colony Formation, and Metalloproteinase-2 Activity in A375 Melanoma Cells: Involvement of P21(Cip1/Waf1) Expression and STAT3 Phosphorylation
}

\author{
Valentina Zanrè ${ }^{1}{ }^{D}$, Rachele Campagnari ${ }^{1}$, Antonietta Cerulli ${ }^{2}$, Milena Masullo ${ }^{2}$, Alessia Cardile ${ }^{1}$, \\ Sonia Piacente ${ }^{2, *}$ and Marta Menegazzi ${ }^{1, * \text { (D) }}$ \\ 1 Department of Neurosciences, Biomedicine and Movement Sciences, Biochemistry Section, University of \\ Verona, Strada Le Grazie, 8, I-37134 Verona, Italy; valentina.zanre@univr.it (V.Z.); \\ rachele.campagnari@univr.it (R.C.); alessia.cardile@studenti.univr.it (A.C.) \\ 2 Department of Pharmacy, University of Salerno, via Giovanni Paolo II n.132, I-84084 Fisciano, Italy; \\ acerulli@unisa.it (A.C.); mmasullo@unisa.it (M.M.) \\ * Correspondence: piacente@unisa.it (S.P.); marta.menegazzi@univr.it (M.M.)
}

check for updates

Citation: Zanrè, V.; Campagnari, R.; Cerulli, A.; Masullo, M.; Cardile, A.; Piacente, S.; Menegazzi, M. Salviolone from Salvia miltiorrhiza Roots Impairs Cell Cycle Progression, Colony Formation, and Metalloproteinase-2 Activity in A375 Melanoma Cells: Involvement of P21(Cip1/Waf1) Expression and STAT3 Phosphorylation. Int. J. Mol. Sci. 2022, 23, 1121. https://doi.org/ $10.3390 /$ ijms 23031121

Academic Editors: Valentina Audrito and Alice Indini

Received: 23 December 2021

Accepted: 17 January 2022

Published: 20 January 2022

Publisher's Note: MDPI stays neutral with regard to jurisdictional claims in published maps and institutional affiliations.

Copyright: (C) 2022 by the authors. Licensee MDPI, Basel, Switzerland. This article is an open access article distributed under the terms and conditions of the Creative Commons Attribution (CC BY) license (https:// creativecommons.org/licenses/by/ $4.0 /)$.

\begin{abstract}
Melanoma is a highly malignant solid tumor characterized by an elevated growth and propagation rate. Since, often, melanoma treatment cannot prevent recurrences and the appearance of metastasis, new anti-melanoma agents need to be discovered. Salvia miltiorrhiza roots are a source of diterpenoid derivatives, natural compounds with several biological activities, including antiproliferative and anticancer effects. Seven diterpenoid derivatives were purified from S. miltiorrhiza roots and identified by NMR and MS analysis. Tanshinone IIA and cryptotanshinone were detected as the main components of $S$. miltiorrhiza root ethanol extract. Although their antitumor activity is already known, they have been confirmed to induce a reduction in A375 and MeWo melanoma cell growth. Likewise, salviolone has been shown to impair the viability of melanoma cells without affecting the growth of normal melanocytes. The underlying anticancer activity of salviolone has been investigated and compared to that of cryptotanshinone in A375 cells, showing an increased P21 protein expression in a P53-dependent manner. In that way, salviolone, even more than cryptotanshinone, displays a multitarget effect on cell-cycle-related proteins. Besides, it modulates the phosphorylation level of the signal transducer and activator of transcription (STAT)3. Unexpectedly, salviolone and cryptotanshinone induce sustained activation of the extracellular signal-regulated kinases (ERK) $1 / 2$ and the protein kinase B (Akt). However, the blockage of ERK1/2 or Akt activities suggests that kinase activation does not hinder their ability to inhibit A375 cell growth. Finally, salviolone and cryptotanshinone inhibit to a comparable extent some crucial malignancy features of A375 melanoma cells, such as colony formation in soft agar and metalloproteinase- 2 activity. In conclusion, it has been shown for the first time that salviolone, harboring a different molecular structure than tanshinone IIA and cryptotanshinone, exhibits a pleiotropic effect against melanoma by hampering cell cycle progression, STAT3 signaling, and malignant phenotype of A375 melanoma cells.
\end{abstract}

Keywords: cryptotanshinone; tanshinone IIA; diterpenoids; Cdk2; cyclin A2; retinoblastoma protein; P53; Akt; ERK1/2

\section{Introduction}

Malignant melanoma is the most severe type of skin cancer for its high metastatic potential and elevated resistance to therapy [1]. To improve long-term survival in melanoma, the identification of new anti-tumor agents from plants is an attractive strategy. Remarkably, natural antitumor agents show a broad spectrum of mechanisms to hinder cancer progression, as they decrease the proliferation rate of malignant cells, diminish invasiveness and 
neo-angiogenesis, and generally display lower side effects in comparison with conventional antitumor drugs [2].

Salvia is the largest genus of the Lamiaceae family, from which many species excel in traditional medicine for the curative properties of their bioactive components [3]. Salvia miltiorrhiza Bunge, known as Danshen, is considered as one of the most important plants in traditional Chinese medicine [3], with a long history as a medicine as well as a healthy food.

Chemical investigations have shown that $S$. miltiorrhiza contains a large number of diterpenes, including various tanshinone analogues, phenolic compounds (including salvianolic acids and flavonoids), along with triterpenes. Tanshinones are phenolic diterpene compounds characterized by a phenanthrenequinone core extracted from a lipid-soluble fraction of the roots [4]. More than 40 tanshinones, including ortho-quinones (i.e., tanshinone I, tanshinone IIA, dihydrotanshinone, and cryptotanshinone) and para-quinones (i.e., isotanshinone I, isotanshinone IIA, and isocryptotanshinone), have been isolated from $S$. miltiorrhiza roots $[4,5]$. Tanshinone derivatives have attracted the attention of medicinal chemists and clinicians for their anticancer properties [6,7]. Many studies have shown that tanshinones can be used to treat solid tumors and hematological malignancies, as well as to protect against cardiovascular and cerebrovascular diseases [8-11]. A structure-activity relationship between different tanshinones has also been considered [12].

Multiple signaling pathways, including antiproliferative, anti-inflammatory, and antioxidative stress pathways, are involved in their actions as anti-cancer agents [11]. Among the large variety of diterpene quinones studied, tanshinone IIA and cryptotanshinone exhibit the most potent cytotoxic and anti-proliferative effects against many human cancer cells $[7,13,14]$. Indeed, tanshinone IIA induced endoplasmic reticulum stress, finally triggering apoptosis [15]. In contrast, cryptotanshinone has been reported to inhibit many crucial signaling pathways activated in cancer, among them the signal transducer and activator of transcription (STAT) 3 in both renal and tongue squamous cell carcinoma [16,17].

In the past decade, several studies investigated the anti-melanoma effects of tanshinones. Li et al. reported that tanshinone IIA inhibits melanoma progression, migration, and invasion and induces autophagic cell death [18]. In contrast, Chen et al. [19] focused on cryptotanshinone action in two mouse melanoma cell lines. They found that cryptotanshinone blocks melanoma cell cycle progression, although it is unable to induce cytotoxic effects. Conversely, Ye et al. [20], besides a cytostatic effect, reported the cryptotanshinone ability to induce an apoptotic pathway in three human melanoma cell lines. They also demonstrated the cryptotanshinone potential to reduce cell migration, invasion, and colony formation [20], suggesting an anti-metastatic action of this natural product, as well. More recently, an in silico study suggested that cryptotanshinone could affect both nuclear factor kappa B (NF-кB) and STAT3 signaling pathways in melanoma [21]. Certainly, NF-кB and STAT3 play a pivotal role in oncogenesis because they trigger pro-survival signals in many cancer types, including melanoma [22,23].

Herein, the phytochemical investigation of the ethanol extract of Salvia miltiorrhiza roots afforded seven compounds (1-7) (see Figure 1), whose structures were established by the extensive use of 1D and 2D NMR experiments as tanshinone derivatives (1-6) and a benzotropolone-type derivative (7). Moreover, the quantitative determination of compounds 1-7 in the extract of $S$. miltiorrhiza roots was carried out by an analytical approach based on LC-ESI/QTrap/MS, using a sensitive and selective mass tandem experiment called multiple reaction monitoring (MRM).

We assessed their ability to inhibit the viability of A375 and MeWo human melanoma cell lines, and we evaluated their structure-activity relationship. Besides the previously mentioned tanshinones IIA (1) and cryptotanshinone (4), we identified salviolone (7) as an active molecule against melanoma cells. Therefore, we comprehensively investigated on the A375 cell line the salviolone (7) anti-melanoma action in comparison to the more known cryptotanshinone (4) and we identified its principal molecular mechanisms. 
<smiles>Cc1coc2c1C(=O)C(=O)c1c-2ccc2c1CCCC2(C)C</smiles>

tanshinone IIA (1)<smiles>Cc1coc2c1C(=O)C(=O)c1c-2ccc2c1[C@H](O)CCC2(C)C</smiles>

$1 \alpha$-hydroxytanshinone (2)<smiles>Cc1coc2c1C(=O)C(=O)c1c-2ccc2c1C(=O)CCC2(C)O</smiles>

1-oxotanshinone (3)<smiles>CC1COC2=C1C(=O)C(=O)c1c2ccc2c1CCCC2(C)C(F)(F)O[GaH]</smiles><smiles>CC1COC2=C1C(=O)C(=O)c1c2ccc2c1C(O)CCC2(C)C</smiles><smiles>CC1COc2c1ccc1c3c(c(=O)oc(=O)c21)C(C)(C)CCC3O</smiles>

(5) $1 \alpha$-hydroxyanhydride -16R-cryptotanshinone (6)<smiles>Cc1cc2ccc3c(c2cc(O)c1=O)CCCC3(C)C</smiles>

salviolone (7)

Figure 1. Compounds isolated from S. miltiorrhiza roots.

\section{Results}

\subsection{Isolation of Compounds 1-7 from Salvia miltiorrhiza Roots}

The ethanol extract of $S$. miltiorrhiza roots was fractionated on a Sephadex LH-20 column, and the fractions were purified by semipreparative HPLC to afford compounds 1-7 (Figure 1), the structures of which were unambiguously elucidated by NMR spectroscopy (Figures S1-S7; Table S1). In this way, secondary metabolites isolated from $S$. miltiorrhiza roots were determined as diterpenoid compounds tanshinone IIA (1), $1 \alpha$-hydroxytanshinone (2), 1-oxotanshinone (3), cryptotanshinone (4), $1 \beta$-hydroxycryptotanshinone (5), $1 \alpha$-hydroxyanhydride-16R-cryptotans hinone (6), and salviolone (7).

\subsection{Quantitative Analysis of Compounds 1-7 in S. miltiorrhiza Ethanol Extract}

To determine the amount of diterpenoids 1-7 in S. miltiorrhiza ethanol extract, an LC-ESI/QTrap/MS/MS analysis, using MRM mode, was carried out. Multiple reaction monitoring (MRM) is a tandem mass spectrometric technique in which a specific transition from a precursor ion to a product ion is monitored for each compound, assuring a high selectivity and sensitivity [24]. MRM transitions (Table 1) were chosen based on the fragmentation pattern shown by each metabolite.

Table 1. Quantitative results of compounds 1-7 occurring in the EtOH extract of S. miltiorrhiza roots.

\begin{tabular}{|c|c|c|c|c|}
\hline Compound & MRM Transition & $\mathbf{R}^{2}$ & Regression Line & $\mathrm{mg} / 100 \mathrm{~g}$ Roots $\pm \mathrm{SD}$ \\
\hline Tanshinone IIA (1) & $295 \rightarrow 277$ & 0.992 & $y=3.50 \times 10^{3} x+1.15 \times 10^{6}$ & $1361.51 \pm 33.39$ \\
\hline $1 \alpha$-Hydroxytanshinone (2) & $311 \rightarrow 293$ & 0.995 & $y=103 x-4.91 \times 10^{4}$ & $83.00 \pm 1.82$ \\
\hline 1-oxotanshinone $(3)$ & $309 \rightarrow 281$ & 0.996 & $y=170 x-5.12 \times 10^{4}$ & $353.65 \pm 11.08$ \\
\hline Cryptotanshinone (4) & $297 \rightarrow 251$ & 0.995 & $y=4.75 \times 10^{3} x+2.30 \times 10^{6}$ & $1379.00 \pm 55.72$ \\
\hline $1 \beta$-Hydroxycryptotanshinone (5) & $313 \rightarrow 267$ & 0.994 & $y=2.72 \times 10^{3} x+6.63 \times 10^{5}$ & N.D. \\
\hline $1 \alpha$-Hydroxyanhydride- $16 R$-cryptotanshinone (6) & $329 \rightarrow 267$ & 0.991 & $y=1.73 \times 10^{3} x+2.26 \times 10^{4}$ & $20.44 \pm 0.89$ \\
\hline Salviolone (7) & $269 \rightarrow 251$ & 0.992 & $y=96.2 x+3.675 \times 10^{4}$ & $31.60 \pm 0.78$ \\
\hline
\end{tabular}

Tanshinone IIA (1) and 1 $\alpha$-hydroxytanshinone (2) showed pseudomolecular ions $[\mathrm{M}+\mathrm{H}]^{+}$at $m / z 295$ and 311, respectively. They were characterized by the same MS/MS fragmentation pattern originating from the main fragment ion $\left[\mathrm{M}+\mathrm{H}-\mathrm{H}_{2} \mathrm{O}\right]^{+}$, due to the neutral loss of water; thus this fragment ion was chosen for MRM analysis. For 1-oxotanshinone (3), the ion $[\mathrm{M}+\mathrm{H}-\mathrm{CO}]^{+}$at $m / z 281$ was the predominant fragment ion obtained from the pseudomolecular ion at $m / z$ 309. Thus, this fragment ion was chosen for MRM analysis. 
Cryptotanshinone (4) and $1 \beta$-hydroxycryptotanshinone (5) displayed pseudomolecular ions $[\mathrm{M}+\mathrm{H}]^{+}$at $m / z 297$ and 313, respectively. They were characterized by a key fragment ion $\left[\mathrm{M}+\mathrm{H}-\mathrm{H}_{2} \mathrm{O}-\mathrm{CO}\right]^{+}$at $\mathrm{m} / \mathrm{z} 251$ and 267 , respectively, due to successive losses of $\mathrm{H}_{2} \mathrm{O}$ and CO. $1 \alpha$-hydroxyanhydride- $16 R$-cryptotanshinone (6) with the pseudomolecular ion $[\mathrm{M}+\mathrm{H}]^{+}$at $\mathrm{m} / \mathrm{z} 329$ displayed the main product ion at $\mathrm{m} / \mathrm{z} 267$, which was selected for MRM analysis. Finally, the fragmentation pattern of salviolone (7) was characterized by the neutral loss of water, producing an intense fragment ion $\left[\mathrm{M}+\mathrm{H}-\mathrm{H}_{2} \mathrm{O}\right]^{+}$at $m / z 251$.

Based on the transitions selected for MRM experiments, the amount $(\mathrm{mg} / 100 \mathrm{~g})$ of each selected compound in S. miltiorrhiza roots was determined. Compounds 1-7 are present in the concentration range of 20.44-1379.00 (mg/100 g).

2.3. A375 and MeWo Melanoma Cell Viability was Affected by Tanshinone IIA, Cryptotanshinone, and Salviolone Extracted from Salvia miltiorrhiza Roots

Anti-melanoma activity of tanshinone IIA (1) and cryptotanshinone (4) has already been reported by several authors [18-20,25]. To attest the ability of compounds purified from S. miltiorrhiza to affect A375 and MeWo cell viability, we compared the activity of the more studied tanshinone IIA (1) and cryptotanshinone (4) with those of $1 \alpha$ hydroxytanshinone (2), 1-oxotanshinone (3), $1 \beta$-hydroxycryptotanshinone (5), $1 \alpha$-hydroxya nhydride-16R-cryptotanshinone (6), and salviolone (7). For tanshinone IIA (1) and cryptotanshinone (4), we used a range of concentrations deducted from the literature data, while for the other compounds, concentrations in a range of 5-50 $\mu \mathrm{M}$ were chosen from preliminary results.

In preliminary experiments, the evaluation of cell viability at different time after compound administration was carried out with sulforhodamine B (SRB) assay. Indeed, after 24-, 48-, and 72-h treatment, an evident time dependence in the inhibition of cell growth was registered (data not shown). Thus, to evaluate A375 and MeWo cell viability, we decided to perform further SRB experiments with each compound only after $72 \mathrm{~h}$.

Our results showed a remarkable ability of tanshinone IIA to inhibit melanoma cell viability in a low micromolar range of concentration.

The half maximal effective concentration $\left(\mathrm{EC}_{50}\right)$ able to reduce cell viability in the A375 melanoma cell line was about $1 \mu \mathrm{M}$ for tanshinone IIA (1), $14 \mu \mathrm{M}$ for cryptotanshinone (4), $17 \mu \mathrm{M}$ for salviolone (7), and $42 \mu \mathrm{M}$ for $1 \beta$-hydroxycryptotanshinone (5) (Figure 2). Instead, in the case of MeWo cell line, the $\mathrm{EC}_{50}$ useful in diminishing cell viability was $2 \mu \mathrm{M}$ for (1), $17 \mu \mathrm{M}$ for (4), $22 \mu \mathrm{M}$ for (7), and $45 \mu \mathrm{M}$ for (5) (Figure 2). For its high $\mathrm{EC}_{50}$ value, compound 5 has been considered poorly active and so its mode of action has not been further investigated. However, 1-oxotanshinone IIA (3), 1-hydroxytanshinone (2), and $1 \alpha$-hydroxy-anhydride- $16 R$ cryptotanshinone (6) were found to be ineffective at least until the concentration of $40 \mu \mathrm{M}$ (Figure 2).

Thereafter, we decided to deepen the study of salviolone due to the novelty of its effect. The activities of salviolone on A375 melanoma cells have been compared with those of the well-studied cryptotanshinone. A375 cells were treated with the same concentrations of either salviolone or cryptotanshinone for their similarity in the $\mathrm{EC}_{50}$ values. 


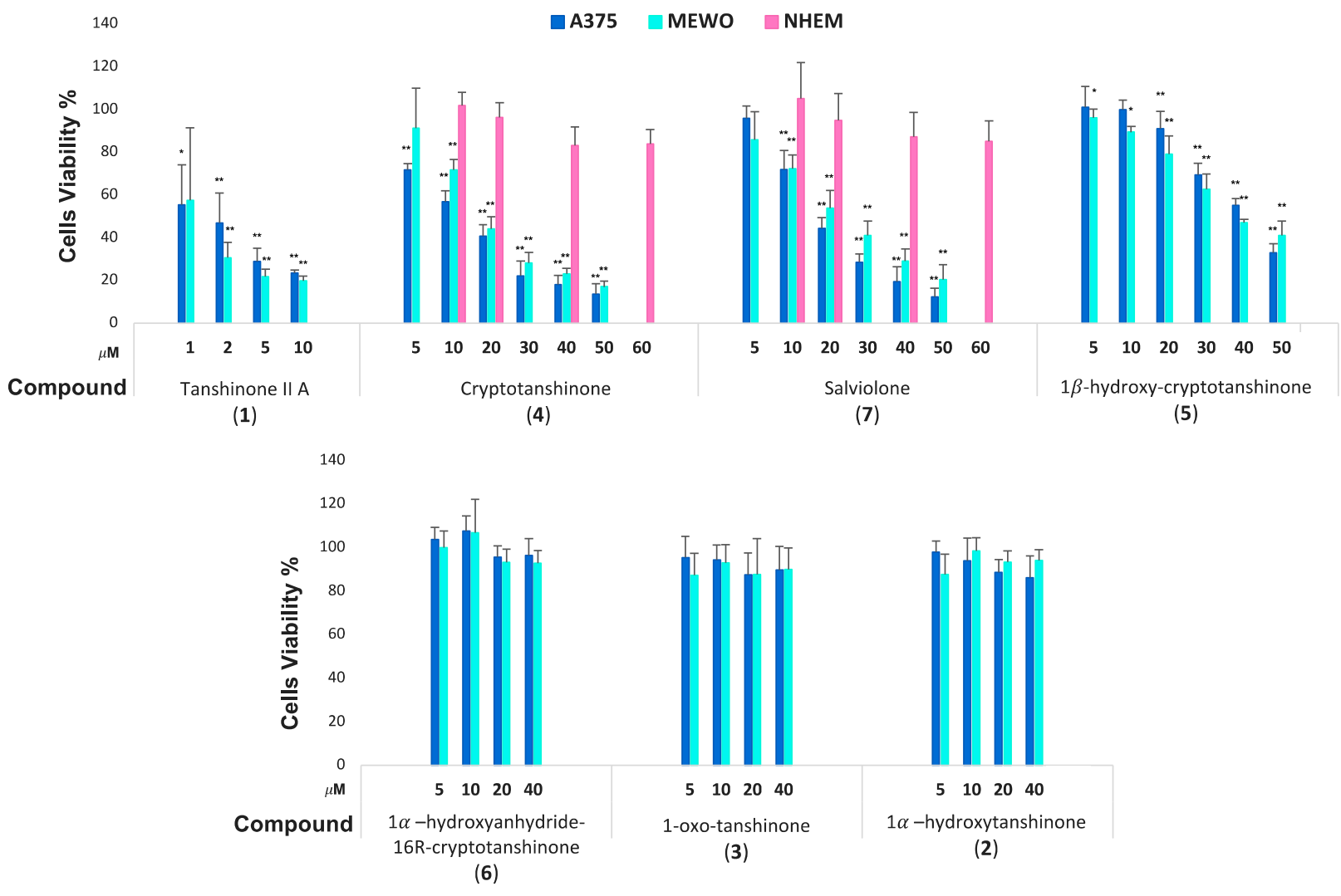

Figure 2. SRB cell viability assay in A375, MeWo melanoma cells, and NHEM cells in the presence of diterpene compounds. SRB viability assay of MeWo (light blue) and A375 (blue) melanoma cell lines with compounds 1-7. SRB viability assay of the normal human epithelial melanocyte (NHEM) cell line (pink) with compounds 4 and 7. Data acquired calculating the average \pm SD of values obtained from three to four independent experiments were compared to data from non-treated control $\left({ }^{*} p<0.05 ;{ }^{* *} p<0.01\right)$.

\subsection{Salviolone and Cryptotanshinone Did Not Affect NHEM Cell Viability}

To investigate whether salviolone (7) in comparison with cryptotanshinone (4) can inhibit normal human epithelial melanocyte growth, the effect of increasing concentrations of the compounds 7 and 4 on cell viability was measured by an SRB assay. Salviolone and cryptotanshinone did not affect NHEM viability at 10-20 $\mu \mathrm{M}$, the concentrations near the $\mathrm{EC}_{50}$ values found for both compounds in A375 and MeWo melanoma cell lines. Higher concentrations $(40-60 \mu \mathrm{M})$ of salviolone (7) or cryptotanshinone (4) can reduce NHEM viability by only $20 \%$ compared to $70-80 \%$ of viability reduction in melanoma cells at the same concentrations (Figure 2). Data suggest that salviolone (7) as well as cryptotanshinone (4) inhibit cell growth with higher selectivity for melanoma cells than normal melanocytes.

Therefore, we decided to investigate the molecular mechanisms underlying the antimelanoma effect of salviolone (7) in comparison to the best-studied cryptotanshinone (4).

\subsection{Signaling Pathways Involved in the Salviolone and Cryptotanshinone Anti-Melanoma Activity}

To elucidate the mechanisms underlying the 7- and 4-induced cell growth inhibition, several signaling pathways involved in malignant melanoma A375 cell growth have been investigated.

\subsubsection{Salviolone and Cryptotanshinone Affect A375 Cell Cycle Progression}

The downregulation of crucial cell-cycle-related proteins could explain the inhibition of melanoma cell viability by the active compounds. 
Progression through the cell cycle requires cyclin-dependent kinase (Cdks) activation, hyper-phosphorylation of retinoblastoma protein $(\mathrm{pRb})$, and sequential expression of cyclins [26].

The A375 cell line treated for 48 or $72 \mathrm{~h}$ with $20 \mu \mathrm{M}$ cryptotanshinone (4) slightly reduced the expression of the active forms of Cdk2 ( $\mathrm{pCdk} 2)$ and cyclin $\mathrm{A} 2$, as well as the phosphorylation of $\mathrm{Rb}$ (Figure 3 ). Salviolone (7) more powerfully affected cell-cyclerelated protein expression than cryptotanshinone (4). Indeed, $20 \mu \mathrm{M}$ salviolone (7) strongly reduced $\mathrm{pRb}, \mathrm{pCdk} 2$, and cyclin A2 expression levels in A375 cells treated for 48 or $72 \mathrm{~h}$ (Figure 3).

A

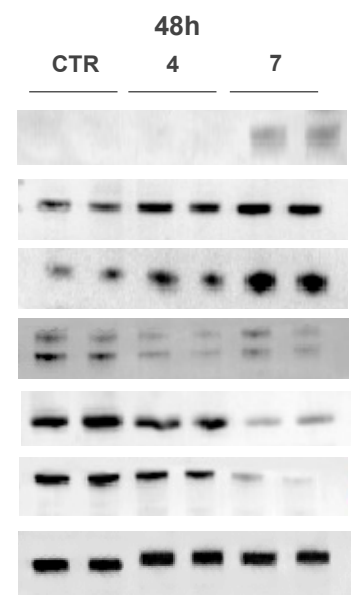

B $48 \mathrm{~h}$

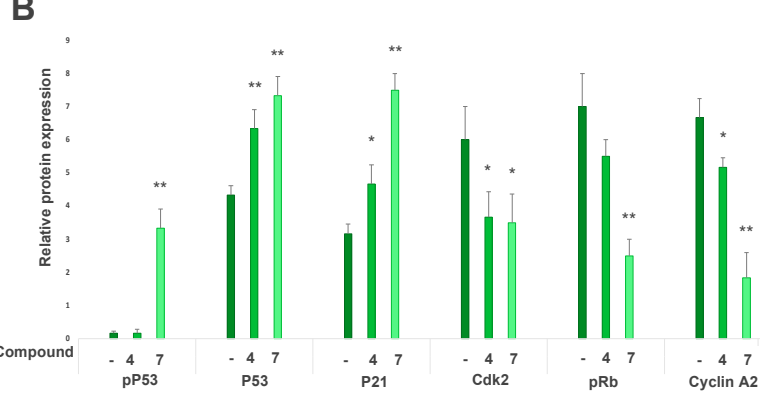

P21

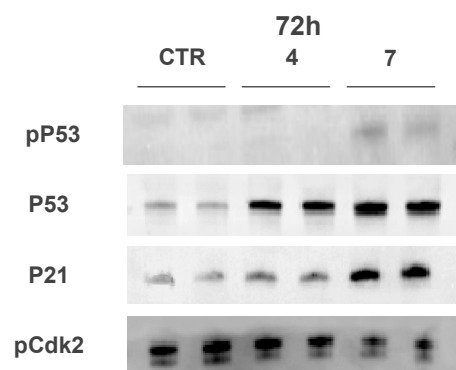

$\mathrm{pRb}$

Cyclin A2

Actin
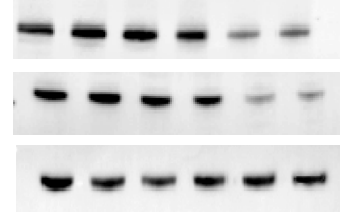

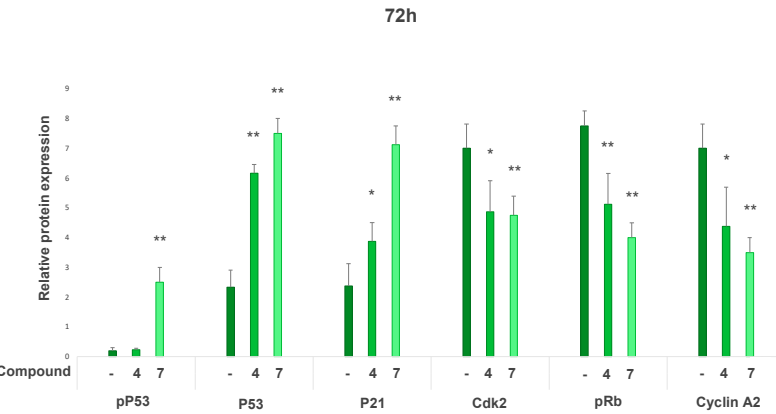

Figure 3. Cryptotanshinone (4) and salviolone (7) effect on the protein expression involved in cell cycle progression and pro-survival signaling. A375 melanoma cells were cultured in the presence $(20 \mu \mathrm{M})$ or absence of salviolone (7) or cryptotanshinone (4) for 48 and $72 \mathrm{~h}$. (A) Representative immunoblot showing the expression level of cell-cycle-related proteins; (B) histograms show the mean values \pm SD of the protein expression level measured by densitometry deriving from three to four independent experiments. All comparisons were performed vs. each control sample after normalization with $\beta$-actin expression, ${ }^{*} p<0.05 ;{ }^{* *} p<0.01$.

To identify the pathways involved in the inhibition of these cell-cycle-related proteins, we measured the expression of the Cdk-inhibitor P21(Cip1/Waf1). P21 can hamper the course of the cell cycle by binding Cdks and blocking their activity [27].

After 48 and $72 \mathrm{~h}$, the P21 expression level significantly increased in A375 cells treated with $20 \mu \mathrm{M}$ cryptotanshinone (4) and strongly increased with salviolone (7) treatment at the same concentration (Figure 3).

Since P21 expression can be upregulated in a P53-dependent or P53-independent manner [28], we investigated the P53 expression and activation level. Immunoblots, carried out at 48 and $72 \mathrm{~h}$ after the administration of either compound 7 or compound 4 , showed a significant increase in P53 protein expression (Figure 3). The pSer15-P53 (pP53) expression level was higher in salviolone-treated A375 cells in comparison with that in untreated samples (Figure 3). Conversely, no significant increase in the P53 phosphorylation level was detected with cryptotanshinone treatment at the same concentration (Figure 3). 
Data suggest that after 48 and $72 \mathrm{~h}$ of treatment, salviolone more than cryptotanshinone could be able to induce the expression of P21 by stabilizing the tumor-suppressor P53 protein amount as well as by activating its phosphorylation.

\subsubsection{Salviolone and Cryptotanshinone Affect Pro-Survival Pathways in the A 375 Cell Line}

The STAT3 pathway is an important target for therapy in the majority of tumors, and it is hyper-activated in cells and tissue samples from melanoma [29]. Therefore, we investigated whether salviolone (7) and cryptotanshinone (4) can affect STAT3 activation.

A prerequisite for STAT3 transcriptional activity is its phosphorylation. The phosphorylation on tyrosine 705 is a crucial event triggering the transcription of many STAT3 target genes, although another phosphorylation site is the serine 727 residue [30].

An immunoblot performed after 72-h culture in the presence of either compound 7 $(20 \mu \mathrm{M})$ or compound $4(20 \mu \mathrm{M})$ showed a significant reduction in Tyr705-STAT3 phosphorylation in comparison to untreated cells (Figure 4). Unexpectedly, the p-Ser727-STAT3 level showed an increase after 72-h treatment (Figure 4).

A

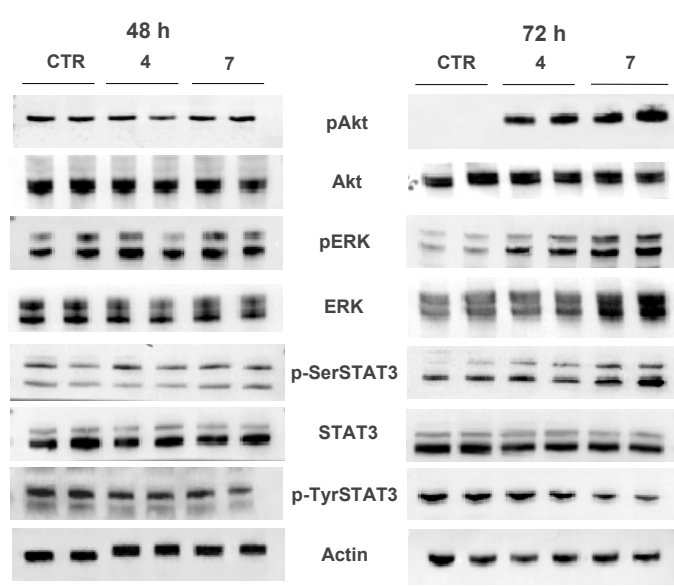

B
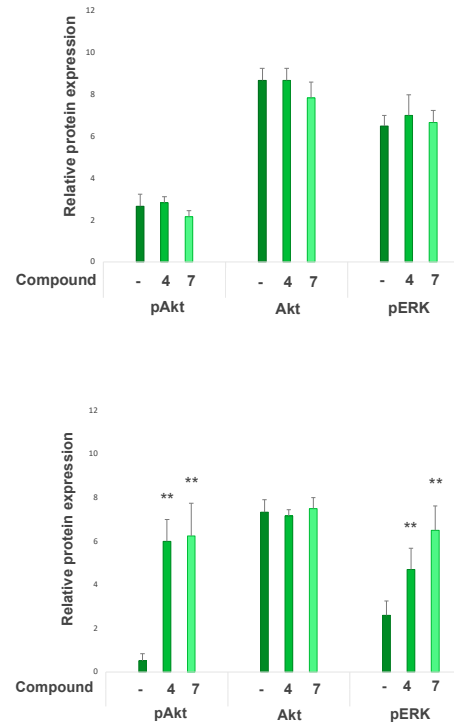

$48 \mathrm{~h}$

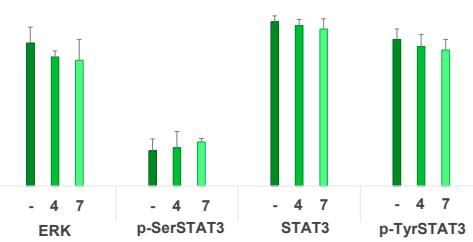

$72 \mathrm{~h}$

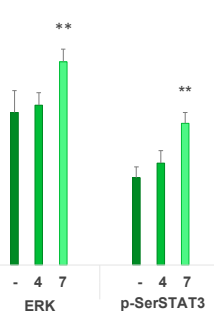

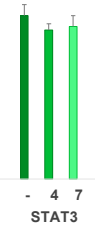

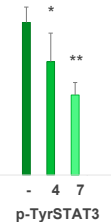

Figure 4. Cryptotanshinone (4) and salviolone (7) effect on protein expression involved in prosurvival signaling. A375 melanoma cells were cultured in the presence $(20 \mu \mathrm{M})$ or absence of cryptotanshinone (4) or salviolone (7) for 48 and $72 \mathrm{~h}$. Immunoblots show the expression levels of (A) the activated and total forms of the signal transducer and activator of transcription (STAT)3, the extracellular signal-regulated kinases (ERK)1/2 and the protein kinase B (Akt); (B) histograms show the mean values \pm SD of the protein expression level measured after 48 or $72 \mathrm{~h}$ deriving from three to four independent experiments. All comparisons were performed vs. each control sample after normalization with $\beta$-actin expression. ${ }^{*} p<0.05$; ${ }^{* *} p<0.01$.

Several serine-threonine kinases can be responsible for Ser727-STAT3 phosphorylation [31], among them, extracellular-signal-regulated kinases (ERK1/2), and the phosphoino sitide-3-kinase/protein kinase B (Akt)/mechanistic target of rapamycin (mTOR) pathways has a key role [31,32]. In A375 cells cultured for 48 h, STAT3 was constitutively activated by the presence of both tyrosine and serine phosphorylation, but it did not significantly change its activity with both treatments. Likewise, ERK1/2 and Akt were in their phosphorylated and activated states in all samples (treated and control). Instead, after 72-h culture, the expression level of pERK1/2 and pAkt declined in the control sample, whereas it remained high in A375 cells treated with either salviolone (7) or cryptotanshinone (4) (Figure 4). It must be noted that although the expression level of Akt total protein was not changed with 
both treatments after 48 and $72 \mathrm{~h}$, the total protein amount of ERK1/2 increased only with salviolone after 72-h treatment parallel to the increase in its phosphorylated form (Figure 4).

\subsection{Effect of MEK1-Inhibitor U0126 and PI3K-Inhibitor LY294002 on A375 Cells Treated with Salviolone or Cryptotanshinone}

We demonstrated that salviolone (7) or cryptotanshinone (4) elicits the phosphorylation of ERK1/2 and Akt in A375 cells. Thus, we verified the effect of ERK1/2 or Akt activity on cell growth. In this regard, we blocked ERK1/2 activation using $10 \mu \mathrm{M}$ U0126, a selective inhibitor of the ERK-upstream kinase MEK1 [33]. Moreover, we hindered Akt activation with $10 \mu \mathrm{M}$ LY294002, an inhibitor of PI3K [34]. In addition, 72-h culture of A375 cells in the presence of U0126 or LY294002 administered alone inhibited A375 cell viability in a concentration-dependent manner (Figure $5 \mathrm{~A}$ ). However, the administration of $10 \mu \mathrm{M}$ U0126 or LY294002 to the culture medium $2 \mathrm{~h}$ before either $20 \mu \mathrm{M}$ salviolone (7) or cryptotanshinone (4) addition did not potentiate the decrease of A375 cell viability induced by the two diterpene compounds (Figure 5A). As expected, immunoblot data attested that $10 \mu \mathrm{M}$ U0126 co-administered with either compound 4 or compound 7 at $20 \mu \mathrm{M}$ strongly inhibited the expression level of pERK1/2 (Figure 5B). Likewise, $10 \mu \mathrm{M}$ LY294002 co-administration with compound 7 or 4 at $20 \mu \mathrm{M}$ induced an inhibition of the pAkt expression level (Figure 5B). Data suggest that the persistent activation of ERK1/2 and Akt, elicited by salviolone (7) or cryptotanshinone (4), does not represent a pro-survival signaling for the A375 cell line.

A

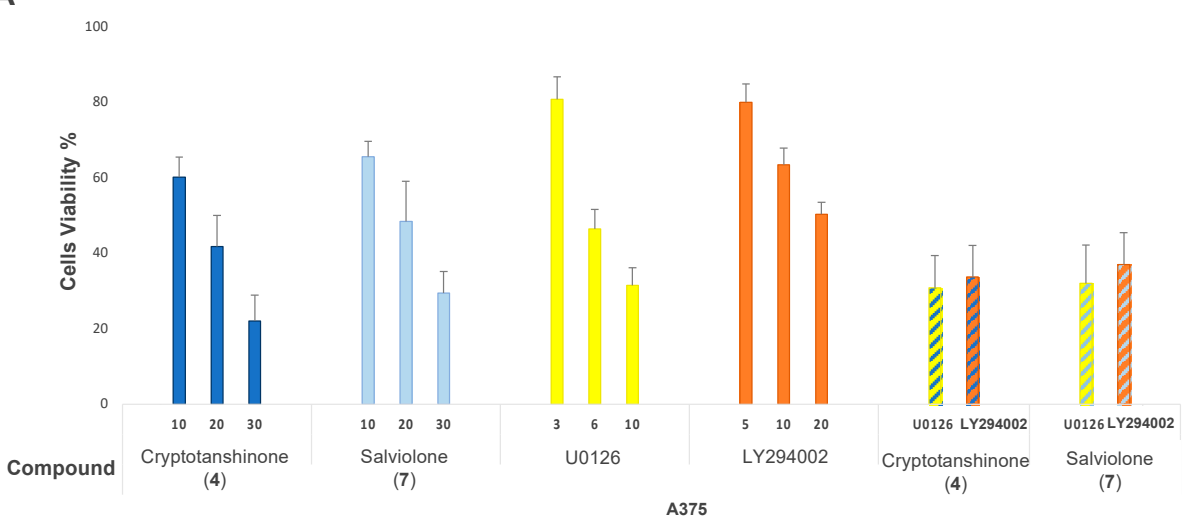

B

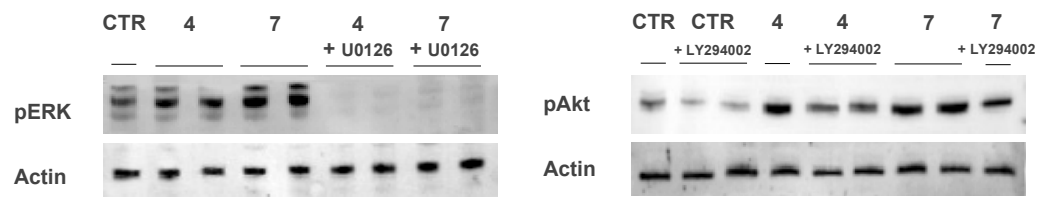

Figure 5. Cell viability of salviolone or cryptotanshinone treatment in the presence or absence of ERK1/2 or Akt inhibitors. (A) SRB assay compares the effects on A375 cell viability of 72-h treatment with salviolone (7) (light blue) or cryptotanshinone (4) (blue) alone, U0126 (yellow) or LY294002 (orange) alone, and compound 7 or $4(20 \mu \mathrm{M})$ plus ERK1/2- or Akt-inhibitor $(10 \mu \mathrm{M})$ co-administration (striped yellow and striped orange, respectively). (B left) Immunoblot attests the inhibitory effect of U0126 $(10 \mu \mathrm{M})$ on ERK1/2 activation in a co-treatment with $20 \mu \mathrm{M}$ cryptotanshinone (4) or salviolone (7). (B, right) Immunoblot attests the inhibitory effect of LY294002 $(10 \mu \mathrm{M})$ on Akt activation in a co-treatment with $20 \mu \mathrm{M}$ cryptotanshinone (4) or salviolone (7). Data acquired calculating the average \pm SD of values obtained from three to four independent experiments were compared to data from non-treated control. 
2.7. Salviolone and Cryptotanshinone Inhibit the Ability of A375 Cells to Form Colonies in Soft Agar

To investigate the salviolone (7) and cryptotanshinone (4) capability to inhibit melanoma cell growth in an anchorage-independent manner, a soft agar colony formation assay was performed. After 21-day culture, either salviolone (7) or cryptotanshinone (4) at 5 and $10 \mu \mathrm{M}$ decreased the number and dimension of colonies formed on soft agar (Figure 6A).

A

$$
\text { Compound }
$$
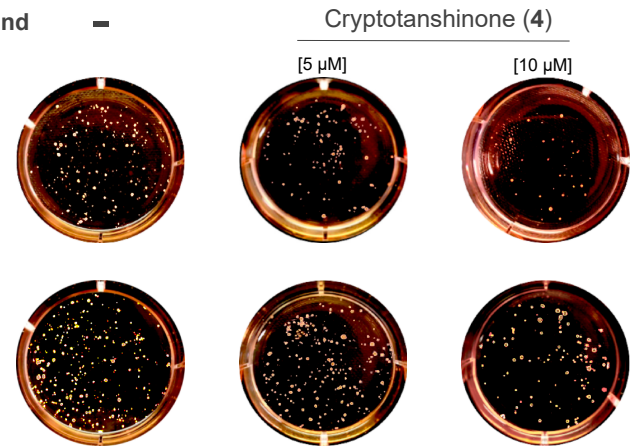

Compound

-

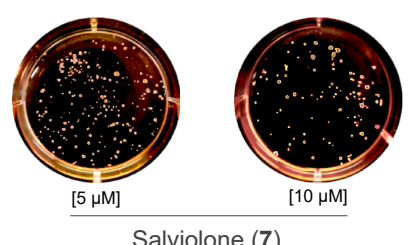

B

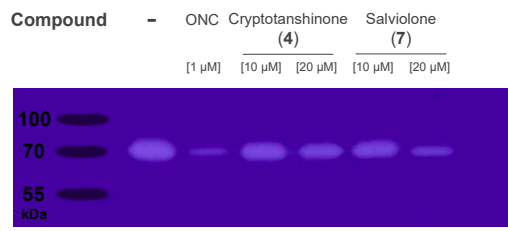

C

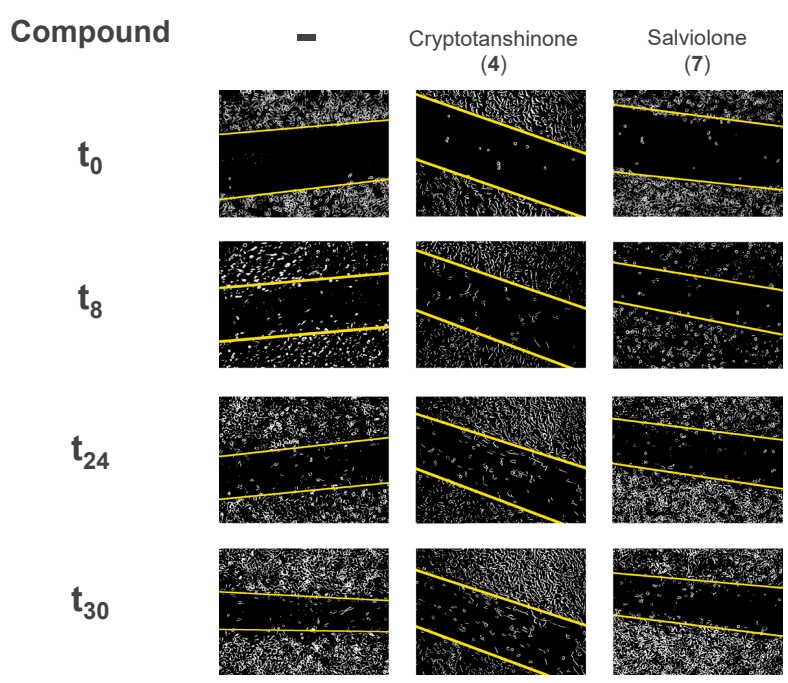

Figure 6. Cryptotanshinone (4) and salviolone (7) effect on colony formation, digestion of extracellular matrix, and migration. (A) A colony formation assay of A375 melanoma cells with 5 and $10 \mu \mathrm{M}$ cryptotanshinone (4) or salviolone (7) cultured for 21 days in soft agar. (B) A gel zymography assay showing the ability of cryptotanshinone (4) or salviolone (7) to inhibit the metalloproteinase (MMP)2 gelatinase activity in A375 cells. (C) A wound healing assay attesting the inhibition of cell mobility with $20 \mu \mathrm{M}$ cryptotanshinone (4) in the A375 cell line. Images were captured with Zeiss Axio Vert $(10 \times)$ at time $0,8,24$, and $30 \mathrm{~h}$ after the administration of each compound. For A, B, and C, the images reported a representative picture of three independent experiments. 


\subsection{Salviolone and Cryptotanshinone Inhibit Matrix Metalloproteinase 2 (MMP2) Activity in A375 Cells}

A gel zymography assay can measure the ability of matrix metalloproteinases (MMPs) to digest their substrate gelatin present in the gel. Thus, the zymographic approach allows sensitive and quantifiable analysis of the activity of MMPs that can be recognized by their molecular weight [35]. Gel zymography data attested that MMP2 is the most active gelatinase present in A375 control cells (Figure 4B). Both compounds 7 and 4 at 10 and $20 \mu \mathrm{M}$ inhibited MMP2 gelatinase activity in the A375 melanoma cell line (Figure 6B).

\subsection{Cryptotanshinone but Not Salviolone Inhibits A375 Cell Migration}

The wound healing assay is widely used to measure cell migration. The method is based on quantifying the rate at which cells can close an artificial scratch created in a confluent cell monolayer.

Figure $6 \mathrm{C}$ shows the ability of $20 \mu \mathrm{M}$ cryptotanshinone (4) to slow down the migration rate of A375 cells. Instead, in comparison to controls, the presence in the cell culture medium of salviolone (7) did not significantly delay the wound healing closure (Figure 6C).

\section{Discussion}

The phytochemical investigation of S. miltiorrhiza roots allowed us to isolate seven compounds (1-7) belonging to the diterpene class. Their structures have been characterized based on NMR experiments along with MS analysis. Tanshinone IIA (1), $1 \alpha-$ hydroxytanshinone (2), 1-oxotanshinone (3), cryptotanshinone (4), and 1 $\beta$-hydroxycryptota nshinone (5) represent tanshinone derivatives characterized by an ortho-quinone system on the tetrahydrophenantrene core and different oxidations at $\mathrm{C}-1$ of the $\mathrm{A}$ ring. The $\mathrm{D}$ ring is a furan in compounds 1-3 and a dihydrofuran in compounds $\mathbf{4}$ and $\mathbf{5}$. Chemically, in $1 \alpha$-hydroxyanhydride- $16 R$-cryptotanshinone (6) ortho-quinone, the tetrahydrophenantrene moiety is modified to be an anhydride group. Salviolone (7) is a rare bisnorditerpene with a benzotropolone chromophore. It represents the first tropolone-type compound isolated from S. miltiorrhiza [36].

With the aim to quantify secondary metabolites isolated in the ethanol extract of $S$. miltiorrhiza roots, a quantitative determination by LC-ESI/QTrap/MS system, in positive ion mode, was carried out. LC-ESI/Qtrap/MS analysis using a multiple reaction monitoring (MRM) experiment is considered one of the most suitable techniques for the quantification of metabolites. In agreement with literature data, tanshinone IIA (1) and cryptotanshinone (4) exhibit the highest concentrations in S. miltiorrhiza roots, followed by 1-oxotanshinone (3) (Table 1); therefore, they represent the chemical markers of S. miltiorrhiza roots [37]. $1 \alpha$-hydroxytanshinone (2), $1 \alpha$-hydroxyanhydride-16R-cryptotanshinone (6), and salviolone (7) occurred in lower amounts; $1 \beta$-hydroxycryptotanshinone (5) was not quantified, since its amount in the ethanol extract of S. miltiorrhiza roots was found to be below the LOD value of the applied method.

Melanoma is a highly malignant solid tumor characterized by an elevated growth and propagation rate [1]. Surgical removal and chemotherapy are the conventional treatments. However, these treatments cannot often prevent recurrences or the appearance of metastasis. Therefore, to eradicate the disease, new anti-melanoma agents exhibiting low toxicity in normal cells should be discovered.

To this aim, we tested diterpene compounds 1-7 on two human melanoma cell lines concerning their ability to inhibit malignant cell growth.

Even though the highly active compounds tanshinone IIA (1) and cryptotanshinone (4) are also the most representative compounds in terms of amount, in this work, the bioactivity profiles of the less explored compounds 2-3 and 5-7 have been investigated. Our results show the ability of the benzotropolone derivative salviolone (7) to inhibit A375 and MeWo cell viability with effectiveness comparable to that of cryptotanshinone (4). Although showing a different skeleton, salviolone (7) has a common structural feature with tanshinone IIA (1) and cryptotanshinone (4), which is the absence of the oxygenated 
function at C-1 of ring A, occurring in compounds 2-3 and 5-6, which were almost inactive. Thus, this characteristic seems to be crucial for the investigated activity.

Therefore, we decided to better explore the anti-melanoma activity of salviolone since no reports are so far available on its effectiveness in melanoma cells.

Remarkably, treatment with either salviolone (7) or cryptotanshinone (4) at $20 \mu \mathrm{M}$ for $72 \mathrm{~h}$ showed about 50\% inhibition of A375 and MeWo melanoma cell viability (Figure 2). However, salviolone (7) and cryptotanshinone (4) administration proved to be safe for culture of normal human epithelial melanocytes (NHEM) because 72-h treatment with these compounds at 40-60 $\mu \mathrm{M}$ did not affect NHEM growth (Figure 2). Data suggest that compounds 7 and 4 could display elevated specificity to block the highly proliferating malignant cell growth while preserving at the same time normal cell viability.

Among the two melanoma cell lines used in this study, A375 is the most highly malignant because it displays low time of duplication, shows the activation of multiple oncogenic pathways, and carries a high pathogenic mutation in the BRAF gene [38,39]. Therefore, we chose A375 cells to investigate the molecular mechanisms underlining the growth inhibition induced by salviolone administration in comparison to that by cryptotanshinone using the same concentrations for each compound.

Cell cycle deregulation is a hallmark of cancer, resulting in accelerated cell duplication, for which cell-cycle-related proteins are sensible targets for tumor therapy.

Progression of the cell cycle is a tightly regulated process that involves the sequential activation and inhibition of Cdks [40] and hyper-phosphorylation of Rb, which induces cyclins expression, allowing the cells to advance in the cell cycle [40].

In A375 cells, 48- and 72-h treatment with salviolone (7) or cryptotanshinone (4) induced a significant increase in both P53 and P21(Cip1/Waf1) expression levels (Figure 3). In addition, salviolone but not cryptotanshinone was able to enhance the phosphorylation level of P53, increasing the tumor suppressor activity of the protein (Figure 3). All these effects can mediate a P53-dependent A375 growth inhibition. Accordingly, high levels of P53 and/or P21 protein expression have been found in cryptotanshinone-treated culture of cell lines derived from tongue squamous carcinoma [17], hepatocellular carcinoma [41], and mouse melanoma [19]. Salviolone's impact on P53 and P21 in any tumor model is unknown since the anticancer effect of salviolone is poorly investigated. We firstly report here salviolone's capability to affect human melanoma cell growth and its competence to increase P21 and P53 protein expression and activity.

To explore the targets of p53 and p21 activity, we analyzed the expression or activation of some cell-cycle-related proteins in A375 cells treated with salviolone (7) and cryptotanshinone (4) in comparison with that in not-treated control ones. Our data showed that salviolone and, to a lesser extent, cryptotanshinone were able to decrease $\mathrm{Rb}$ phosphorylation, Cdk2 activation, and cyclin A2 expression at both 48 and 72 h (Figure 3).

Our data demonstrated a multitarget activity of salviolone (7) and cryptotanshinone (4) on cell-cycle-related proteins. This multiple regulation is not surprising since it is mediated by the high expression of P21, which can inhibit several Cdks involved in either the G1 or the $S$ phase of the cell cycle [26]. Indeed, the low expression level of cyclin A2 found by us in A375 cells treated with salviolone (7) is consistent with the results of Zhang et al. [42], who previously reported the salviolone potential to arrest G2/M transition in the HeLa cell line. Furthermore, some papers have demonstrated either G1/S or G2/M cell cycle arrest with cryptotanshinone (4) in many cancer cell lines [41,43], including a mouse melanoma cell line [19].

The transcription factor STAT3 has a key role in the onset and progression of cancer. Actually, in a mouse model, the silencing of STAT3 expression results in melanoma growth inhibition [44]. Certainly, the activation of STAT3 elicits the expression of many target genes that are involved in cell proliferation, apoptosis, metastasis, inflammation, immunity, and angiogenesis [45]. STAT3 transcriptional activity is triggered by many different kinases able to phosphorylate its tyrosine 705 and serine 727 residues [46]. STAT3 tyrosine phosphorylation seems to be the most important activating event. Phosphorylation of Tyr705-STAT3 can 
result from the activity of either non-receptor tyrosine kinases or tyrosine kinase receptors after binding to their specific cytokine or growth factor [46]. However, the biological role of p-Ser727-STAT3 is not completely known. The cross talk between STAT3 phosphorylation at these two different sites is also unclear since p-Ser727 STAT3 can either positively or negatively modulate tyrosine 705 phosphorylation $[47,48]$.

Our data in the A375 cell line attested that 72-h treatment with salviolone (7) or cryptotanshinone (4) modulated STAT3 activity by decreasing its p-Tyr705 level, although, at the same time, p-Ser727-STAT3 expression was increased (Figure 4). To identify the signaling pathway eliciting this serine phosphorylation increase, the activation status of ERK1/2 and Akt was investigated. The activated forms of these kinases were high at $48 \mathrm{~h}$ in all treated and not-treated samples (Figure 4). Conversely, after $72 \mathrm{~h}$, immunoblot data indicated that this activation disappeared in control samples, whereas high levels of pERK1/2 and pAkt, as well as p-Ser727-STAT3, were maintained in cells treated with salviolone (7) or cryptotanshinone (4) (Figure 4). These results, finally, suggest that the activation of ERK1/2 and Akt is a transient occurrence in not-treated samples but a longlasting event in A375 cells treated with compounds 4 and 7.

In this regard, a negative correlation has been previously found between ERK1/2 activation and the p-Tyr705-STAT3 expression level in pancreatic cancer cells [49]; in addition, ERK or PI3K, the upstream kinase of Akt, can inhibit STAT3 tyrosine phosphorylation in human melanoma cells [50]. Moreover, it has been previously reported in melanoma cells that MEK-inhibitor resistance could also depend on the cross talk between ERK1/2 and Src/Fak/STAT3 signaling pathways [51], although this topic is still debated and context dependent. Usually, the reactivation of ERK1/2 and/or Akt in cancer cells could indicate an adaptation of cells to the cytostatic compound leading to the onset of resistance. In patients with BRAF-mutated melanoma, MEK inhibitors are more frequently used in association with BRAF inhibitors to definitely block ERK activity and the associated cell proliferation [52]. Unfortunately, these treatments do not have long-lasting effectiveness because drug resistance occurs soon [53].

To investigate the role of ERK1/2 and Akt activation, we tested whether the addition of ERK1/2 or Akt inhibitors can affect A375 cell viability in the presence or absence of salviolone (7) or cryptotanshinone (4). Firstly, we attested by an immunoblot that U0126 and LY294002 inhibitors were able to decrease the phosphorylation levels of ERK1/2 and Akt, respectively (Figure 5B). An SRB viability assay demonstrated that either U0126 or LY294002 administered alone decreases A375 cell viability in a concentration-dependent manner, suggesting that the transient ERK1/2 or Akt inhibition led to a slowing rate of cell proliferation. Conversely, co-treatment with each inhibitor at $10 \mu \mathrm{M}$ plus either compound 7 or 4 at $20 \mu \mathrm{M}$ has not registered additive effects on cell viability in comparison with each single treatment (Figure 5A). Data suggest that the salviolone- and cryptotanshinoneinduced sustained activation of ERK1/2 and Akt could be irrelevant regarding the effect elicited by the two diterpene compounds on A375 cell growth. Alternatively, we could suggest that the inhibition of the p-Tyr705-STAT3 level may be the predominant occurrence to slowdown A375 cell proliferation. Furthermore, it should be recalled that the activation of ERK1/2 does not always lead to an increase in cell proliferation. Tsukada et al. indeed have reported in the HepG2 cell line that a strong and long-lasting activation of ERK1/2 results in a paradoxical effect with $\mathrm{Rb}$ hypo-phosphorylation, cell cycle arrest, and proliferation inhibition [54].

Besides cell growth inhibition, salviolone (7) and cryptotanshinone (4) could counteract other important features of A375 melanoma cells related to their high grade of malignancy and ability to metastasize.

Tumor cells can grow in an anchorage-independent manner. Eradication of this capability is required for the prevention of recurrences [55]. Therefore, we measured both salviolone (7) and cryptotanshinone (4) competence to inhibit A375 colony formation in soft agar. We found that 5-10 $\mathrm{MM}$ salviolone (7) and cryptotanshinone (4) reduced the number of colonies present in soft agar in a concentration-dependent manner (Figure 6A), 
thus, suggesting that both compounds can inhibit an important feature of malignant cells, i.e., their ability to grow and divide irrespective of their extracellular matrix contact.

In this regard, salviolone (7) and cryptotanshinone (4) can also inhibit the gelatinase activity of MMP2 in a concentration-dependent modality (Figure 6B). MMPs are proenzymes and need prior activation to be active. The zymography assay used by us can measure only the active forms of MMPs, which are correlated with the potential invasiveness of melanoma cells. Indeed, MMPs can cleave collagen, elastin, and other extracellular matrix components favoring cancer cell spread [56]. Moreover, MMP2 is a direct target gene of STAT3 and both STAT3- and MMP2-activation has been reported to increase the chances of metastasis [57].

The wound healing assay is a standard in vitro technique for probing the collective cell migration rate of closure of an artificial scratch, which is a measure of the speed of motion of the cells. Salviolone (7) was not able to significantly slow down the A375 cell migration rate in comparison to not-treated cells. Instead, as previously reported by Ye et al. [20], cryptotanshinone (4) can significantly slow down the A375 cell migration rate. The migration of cells is due to a multitude of signals and mechanisms that are involved in cancer progression and metastasis. At present, we have not identified the mechanism underlying the different competence levels of the two diterpenes to attenuate cell migration.

\section{Materials and Methods}

\subsection{General Procedures}

NMR experiments were acquired in methanol-d4 (99.95\%, Sigma-Aldrich, Milan, Italy) on a Bruker DRX-600 spectrometer (Bruker BioSpin GmBH, Rheinstetten, Germany) equipped with a Bruker $5 \mathrm{~mm}$ TCI CryoProbe at $300 \mathrm{~K}$. Data processing were carried out with Topspin 3.2 software (Bruker BioSpin, Rheinstetten, Germany).

\subsection{Plant Material}

The powdered roots of S. miltiorrhiza Bunge were purchased by Lymeherbs. On the package, the batch number (SM223030), the expiration data (02/2023), and the condition of storage at room temperature in a dry place are reported. A voucher specimen (n. 157) was deposited at the Department of Pharmacy, University of Salerno.

\subsection{Extraction and Isolation}

The powdered roots of S. miltiorrhiza $(100 \mathrm{~g})$ were milled and macerated at room temperature with ethanol $(3 \times 0.8 \mathrm{~L})$. After filtration and evaporation of the solvent to dryness in vacuo, $7.88 \mathrm{~g}$ of a crude ethanol extract were obtained. The dried ethanol extract $(3.0 \mathrm{~g})$ was fractionated on a Sephadex LH-20 (Pharmacia) column $(100 \times 5 \mathrm{~cm})$, using $\mathrm{MeOH}$ as the mobile phase, affording 60 fractions $(8 \mathrm{~mL})$, monitored by TLC.

Fractions 8-29 were subjected to an RP-HPLC-UV system with a Synergi Hydro RP $80 \mathrm{~A}(250 \times 10 \mathrm{~mm})$. The elution gradient was obtained using water with $0.1 \% \mathrm{formic}$ acid as eluent $\mathrm{A}$ and acetonitrile with $0.1 \%$ formic acid as B at a flow rate of $2.0 \mathrm{~mL} / \mathrm{min}$; the detection wavelength was $280 \mathrm{~nm}$, and the analysis were performed at room temperature. The HPLC gradient was $40 \%$ B for $5 \mathrm{~min}$; from 40 to $80 \%$ B for $35 \mathrm{~min}$; from 80 to $90 \%$ for $5 \mathrm{~min}$; from 90 to $100 \%$ B for $5 \mathrm{~min}$; and, at the end, $100 \%$ B for $10 \mathrm{~min}$; in particular, fractions 8-13 $\left(50.5 \mathrm{mg}\right.$ ) were chromatographed to obtain compound $7\left(5.1 \mathrm{mg} ; t_{R}=22.35 \mathrm{~min}\right)$. Fractions $8-13\left(50.5 \mathrm{mg}\right.$ ) were chromatographed to obtain compound $7\left(5.1 \mathrm{mg} ; t_{R}=22.35 \mathrm{~min}\right)$. Fractions $23-24(65.3 \mathrm{mg})$ gave compound $5\left(3.6 \mathrm{mg} ; t_{R}=16.74 \mathrm{~min}\right)$. Fractions $27-29(100.1 \mathrm{mg})$ were chromatographed to yield compounds $2\left(4.2 \mathrm{mg} ; t_{R}=23.03 \mathrm{~min}\right)$ and $3(3.5 \mathrm{mg}$; $\left.t_{R}=15.07 \mathrm{~min}\right)$. Fractions $30-36(220.6 \mathrm{mg})$ were chromatographed to yield compounds 4 $\left(21.5 \mathrm{mg} ; t_{R}=18.57 \mathrm{~min}\right)$ and $\mathbf{1}\left(24.3 \mathrm{mg} ; t_{R}=21.52 \mathrm{~min}\right)$.

Fractions 37-39 (62.2 $\mathrm{mg})$ were chromatographed by semipreparative HPLC-RI with a

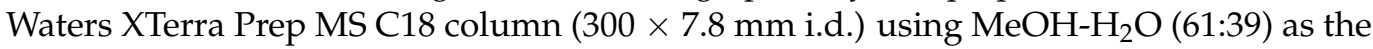
mobile phase to yield compound $6\left(3.8 \mathrm{mg} ; t_{R}=14.00 \mathrm{~min}\right)$. 
To unambiguously identify compounds isolated by HPLC and to discriminate among structural isomers or stereoisomers, structure elucidation by 1D and 2D NMR experiments of isolated compounds was carried out. The purity of these compounds (>99\%) was determined by HPLC analysis.

\subsection{Quantitative Analysis of Compounds 1-7 in S. miltiorrhiza Roots}

Quantitative analysis was performed on an LC-ESI/QTrap/MS system, operating in the multiple reaction monitoring (MRM) mode. The MRM approach firstly targets the ion corresponding to the compound of interest, with the subsequent fragmentation of this target ion to produce a range of daughter ions. One (or more) of these fragment daughter ions can be selected for quantitation purposes. The analysis was performed on a C18 reversed phase (RP) column $(2.1 \times 250 \mathrm{~mm}$; Luna MS C18 $5 \mu \mathrm{m}$; Phenomenex, Aschaffenburg, Germany) kept at $30{ }^{\circ} \mathrm{C}$, using water with $0.1 \%$ formic acid as eluent $\mathrm{A}$ and acetonitrile with $0.1 \%$ formic acid as B at a flow rate of $0.2 \mathrm{~mL} / \mathrm{min}$. The autosampler was set to inject $2 \mu \mathrm{L}$ of the extract $(250 \mathrm{ng} / \mu \mathrm{L})$.

Stock solutions ( $1 \mathrm{mg} / \mathrm{mL}$ ) of isolated compounds used as external standards (ES) were prepared by dissolving each compound in methanol. Each stock solution was diluted with methanol to obtain 10 solutions of different ES concentrations $(0.05,0.5,0.1,1.0,2.5$, $5,10,12.5,17.5$, and $20 \mathrm{ng} / \mu \mathrm{L})$. Calibration curves were constructed by injecting $4 \mu \mathrm{L}$ of each standard solution at each concentration level in triplicate (Table S2). Linear regression analysis was performed using the Analyst 1.6.2 Software provided by the manufacturer (AB Sciex, Milan, Italy).

Linearity was evaluated by correlation values of calibration curves. The limit of quantification (LOQ; equivalent to sensitivity) was evaluated by injecting a series of increasingly diluted standard solutions until the signal-to-noise ratio was reduced to 10 . The limit of detection (LOD) was estimated by injecting a series of increasingly diluted standard solutions until the signal-to-noise ratio was reduced to 3 [58]. The LOD was from 0.035 to $0.086 \mu \mathrm{g} / \mu \mathrm{L}$ and the LOQ from 0.15 to $0.38 \mu \mathrm{g} / \mu \mathrm{L}$.

\subsection{Malignant Melanoma and Normal Melanocyte Cell Culture}

Human MeWo (HTB-65) and A375 (CRL-1619) melanoma cell lines as well as the normal human epidermal melanocyte (NHEM) (PCS-200-013) cell line (ATCC, Manassas, VA, USA) were cultured at $37^{\circ} \mathrm{C}$ under $5 \% \mathrm{CO}_{2}$ in a humidified atmosphere. Roswell Park Memorial Institute 1640 medium (RPMI, Gibco, Ref.21875, Thermo Scientific, Waltham, MA, USA) was used to culture MeWo cells, while Dulbecco's Modified Eagle Medium (DMEM, Gibco, Ref. 61965, Thermo Scientific, Waltham, MA, USA) was used for A375 and NHEM cell lines. The culture media were supplemented with $10 \%$ fetal bovine serum (FBS, Gibco, Thermo Scientific, Waltham, MA, USA) plus 1\% Antibiotic Antimycotic Solution (Gibco, Thermo Scientific). The MEK1 inhibitor U0126 (CAY-70970) and the PI3K inhibitor LY294002 (CAY-70920) were provided by Cayman Chemical, Ann Arbor, MI, USA.

\subsection{Cell Viability Sulforhodamine B Assay}

Melanoma MeWo and A375 cells or NHEM were seeded in 96-well plates $\left(5.0 \times 10^{3}\right.$ cells / well for MeWo cells and $2.9 \times 10^{3}$ cells/well for A375 or NHEM). After 24-h culture, the cells were treated with different concentrations of compounds 1-7. After 72-h treatment, the cells were fixed by adding $25 \mu \mathrm{L} /$ well of $50 \%(w / v)$ TCA directly into the culture medium. The plates were incubated at $4{ }^{\circ} \mathrm{C}$ for $1 \mathrm{~h}$, washed four times with $\mathrm{ddH}_{2} \mathrm{O}$, and dried at RT. Staining was performed by adding $50 \mu \mathrm{L} /$ well of $0.04 \%(w / v)$ sulforhodamine B (SRB) sodium salt solution (Sigma-Aldrich, Milan, Italy). After 1-h incubation at RT, the plates were rinsed with $1 \%$ HAc and air-dried. SRB was solubilized in a $10 \mathrm{mM}$ Tris-base solution pH 10.5 and $\mathrm{Abs}_{492}$ measured in the plate reader TECAN NanoQuant Infinite M200 Pro (Tecan Group Ltd., Männedorf, Switzerland). Six replicates for each condition/data point were performed. 


\subsection{Total Protein Extracts and Sample Preparation for Immunoblot Analysis}

A375 cells were seeded in $6 \mathrm{~cm}$ Petri dishes (190 300 cell/dish) and treated with different compounds at 10 or $20 \mu \mathrm{M}$. After 48- or 72-h treatment, the cells were scraped using warm $1 \times$ sample buffer $(2 \%$ SDS, $10 \%$ glycerol, $50 \mathrm{mM}$ Tris- $\mathrm{HCl}, 1.75 \% \beta$-mercaptoethanol, and bromophenol blue) and boiled at $99{ }^{\circ} \mathrm{C}$ for $10 \mathrm{~min}$. Total protein extracts were kept at $-80{ }^{\circ} \mathrm{C}$ until use.

\subsection{Immunoblot Analysis}

Protein extracts were analyzed with a 7.5 or $10 \%$ polyacrylamide SDS-PAGE and transferred to a polyvinylidene difluoride membrane (PVDF, Thermo Fisher Scientific, Waltham, MA, USA). The membranes were blocked at RT for $1 \mathrm{~h}$ with TBST buffer $(10 \mathrm{mM}$ Tris-HCl $\mathrm{pH} 7.5,100 \mathrm{mM} \mathrm{NaCl}, 0.1 \%$ Tween20) containing 4\% Milk (Formulat). Then, they were incubated on a shaker, overnight $(\mathrm{ON})$ at $4{ }^{\circ} \mathrm{C}$, with $5 \%$ BSA solution containing primary antibodies against p-Tyr705-STAT3 (\#9145, 1:1000), pRb (\#8516, 1:2000), pERK (\#4370, 1:1000), pAkt (\#4060, 1:2000), pSer15-P53 (\#9286, 1:2000) (Cell Signaling Technology, Danvers, CO, USA), Akt (GTX121937, 1:3000), ERK (GTX134452, 1:6000), Cyclin A2 (GTX-103042, 1:3000), p-Thr160Cdk2 (GTX-133862, 1:3000), p21 (GTX-629543, 1:3000) (Genetex, Alton Pkwj Irvine, CA, USA), p53 (Sc-263, 1:1000), STAT3 (Sc-482, 1:1000), and p-Ser727-STAT3 (Sc-136193, 1:1000) (Santa Cruz Biotechnology, Dallas, TX, USA). The membranes were washed three times with TBST buffer for $30 \mathrm{~min}$ and then incubated for $1 \mathrm{~h}$ with a horseradish-peroxidase-conjugated secondary antibody (anti-rabbit 1:6000, Genetex), (anti-mouse, 1:4000, Cell Signaling Technology, Danvers, CO, USA). They were washed another three times for $30 \mathrm{~min}$ with TBST buffer. All protein extracts were normalized with a $\beta$-actin protein antibody (GTX-124214, 1:10,000; Genetex, Alton Pkwj Irvine, CA, USA). Immuno-detection was carried out with an ECL kit (GE-Healthcare, Little Chalfont, UK), and the chemiluminescence signals were detected with ChemiDoc (Bio-Rad, Hercules, CA, USA).

\subsection{Soft Agar Colony Formation Assay}

Before seeding, 6-well plates were prepared with soft agar, as follows: the bottom layer was filled with $1 \%$ low-gelling temperature agarose and 2X DMEM, supplemented with 20\% FBS and 2\% Antibiotic Antimycotic Solution (Gibco, BRL Invitrogen Corp., Carlsbad, CA, USA). After $30 \mathrm{~min}$, cells (5000 cell/well) were suspended in $0.6 \%$ agarose and $2 \mathrm{X}$ DMEM supplemented with 20\% FBS and 2\% Antibiotic Antimycotic Solution (Gibco, BRL Invitrogen Corp., Carlsbad, CA, USA) and placed over the $0.5 \%$ agarose layer. Then, either cryptotanshinone (4) or salviolone (7) at 5-10 $\mu \mathrm{M}$ was added directly into each well and $100 \mu \mathrm{L}$ of fresh media was added twice a week for 3 weeks. The semi-solid cultures were performed in triplicate and images captured.

\subsection{Gelatin Zymography}

A375 cells were cultured in the presence of 10 or $20 \mu \mathrm{M}$ cryptotanshinone (4), salviolone (7), or $1 \mu \mathrm{M}$ onconase (provided by Prof. G. Gotte), as a positive control [59], for $48 \mathrm{~h}$ and then they were serum starved for $24 \mathrm{~h}$. The conditioned medium was collected and $10 \times$ concentrated with an Amicon Ultra-2 Centrifugal filter unit (Merck-Millipore, Milan, Italy). Protein concentrations were determined with Coomassie (Thermo Fisher Scientific, Waltham, MA, USA) and samples treated with a non-reducing sample buffer. To separate proteins, a 7.5\% SDS-PAGE was performed. The gel contained $4 \mathrm{mg} / \mathrm{mL}$ of gelatin (SigmaAldrich, Milan, Italy) and was washed with $50 \mathrm{mM}$ Tris- $\mathrm{HCl} \mathrm{pH} \mathrm{7.5,} 5 \mathrm{mM} \mathrm{CaCl}$, and $1 \mu \mathrm{M}$ ZnCl2 supplemented with 2.5\% Triton X-100 (Serva Electrophoresis, Heidelberg, Germany). It was then kept in the incubation buffer ( $1 \%$ Triton X-100, $50 \mathrm{mM}$ Tris- $\mathrm{HCl} \mathrm{pH}$ $7.5,5 \mathrm{mM} \mathrm{CaCl} 2$, and $1 \mu \mathrm{M} \mathrm{ZnCl} 2)$ for $24 \mathrm{~h}$. This buffer contained the cofactors necessary to maintain the metalloproteinase (MMP)2 gelatinase activity, so that it could degrade the gelatin present in the gel. The gel was stained with 0.5\% Coomassie Brilliant Blue R-250 in $20 \%$ ethanol $/ 10 \%$ acetic acid, and the gelatinase activity was detected by evaluating the presence and intensity of clear bands on the blue background. 


\subsection{Wound Closure Cell Migration Assay}

The wound healing assay is widely used to measure cell migration. A375 cells were seeded in 12-well plates $\left(120 \times 10^{3}\right.$ cells/well $)$ and, once confluence was reached, the monolayer was scratched with a sterile $10 \mu \mathrm{L}$ pipette tip. To remove detached cells, the wells were washed with the complete medium and afterward refilled with a fresh medium containing $0.5 \%$ FBS. Then, either cryptotanshinone (4) or salviolone (7) at 10 or $20 \mu \mathrm{M}$ was added to the culture. After 0-, 8-, 24- and 30-h culture, images were captured with Zeiss Axio Vert. (Zeiss, Milan, Italy) to measure the delay to repopulate the scratch in comparison with the non-treated control sample.

\subsection{Statistics}

All the results are reported as a mean value \pm SD. Unless otherwise noted, the $p$-values were determined using unpaired, two-tailed Student's $t$-test, with one asterisk * if $p<0.05$ and two ** if $p<0.01$. For each type of experiment, a minimum of three independent biological replicates were performed.

\section{Conclusions}

We purified seven natural diterpenoid derivatives from Salvia miltiorrhiza roots, and we analyzed their anti-melanoma activities. Besides the most known anti-melanoma effect of tanshinone IIA (1) and cryptotanshinone (4), we firstly showed that only salviolone (7), among the diterpene compounds, displays high competence to inhibit A375 and MeWo melanoma cell growth without affecting normal melanocyte viability. In A375 cells, the molecular mechanisms of both salviolone (7) and, to a lesser extent, cryptotanshinone (4) pass through a cell cycle hindered by the over-expression of P21 in a P53-dependent manner. This effect results in slowing down cell cycle progression in a multitarget action, including $\mathrm{pRb}, \mathrm{pCdk}$, and cyclin A2 downregulation. Salviolone (7) and cryptotanshinone (4) were also able to decrease the p-Tyr-STAT3 expression level, which can justify the reduction of both MMP2 gelatinase activity and soft agar colony formation, thus lowering A375 malignancy potential. At the same time, salviolone (7) and cryptotanshinone (4) can induce the sustained activation of ERK1/2 and Akt without decreasing their growth-inhibitory effectiveness.

Supplementary Materials: The following are available online at https:/ /www.mdpi.com/article/10 $.3390 /$ ijms23031121/s1.

Author Contributions: Conceptualization, M.M. (Marta Menegazzi) and S.P.; methodology, M.M. (Milena Masullo) and S.P.; formal analysis, A.C. (Antonietta Cerulli), M.M. (Milena Masullo), and V.Z.; investigation, V.Z., R.C., A.C. (Alessia Cardile), A.C. (Antonietta Cerulli), and M.M. (Milena Masullo); writing —original draft preparation, M.M. (Marta Menegazzi) and M.M. (Milena Masullo); writing-review and editing, M.M. (Marta Menegazzi) and S.P.; funding acquisition, S.P. and M.M. (Marta Menegazzi). All authors have read and agreed to the published version of the manuscript.

Funding: This research was funded by "Fighting Cancer resistance: Multidisciplinary integrated Platform for a Technological Innovative Approach to Oncotherapies" (Project B61G18000470007, Campania Oncotherapies) Sonia Piacente and "Fondo unico per la ricerca" (FUR)-Menegazzi.

Institutional Review Board Statement: Not applicable.

Informed Consent Statement: Not applicable.

Data Availability Statement: Not applicable.

Conflicts of Interest: The authors declare no conflict of interest. 


\section{References}

1. Indini, A.; Grossi, F.; Mandalà, M.; Taverna, D.; Audrito, V. Metabolic Interplay between the Immune System and Melanoma Cells: Therapeutic Implications. Biomedicines 2021, 9, 607. [CrossRef]

2. Choudhari, A.S.; Mandave, P.C.; Deshpande, M.; Ranjekar, P.; Prakash, O. Phytochemicals in Cancer Treatment: From Preclinical Studies to Clinical Practice. Front. Pharmacol. 2019, 10, 1614, Corrigendum in Front. Pharmacol. 2020, 11, 175. [CrossRef] [PubMed]

3. Rashed, A.A.; Rathi, D.-N.G. Bioactive Components of Salvia and Their Potential Antidiabetic Properties: A Review. Molecules 2021, 26, 3042. [CrossRef] [PubMed]

4. Jiang, Z.; Gao, W.; Huang, L. Tanshinones, Critical Pharmacological Components in Salvia miltiorrhiza. Front. Pharmacol. 2019, 10, 202. [CrossRef]

5. Zhang, T.; Zhong, S.; Wang, Y.; Dong, S.; Guan, T.; Hou, L.; Xing, X.; Zhang, J.; Li, T. In vitro and in silico perspectives on estrogenicity of tanshinones from Salvia miltiorrhiza. Food Chem. 2019, 270, 281-286. [CrossRef]

6. Gao, H.; Sun, W.; Zhao, J.; Wu, X.; Lu, J.-J.; Chen, X.; Xu, Q.-M.; Khan, I.A.; Yang, S. Tanshinones and diethyl blechnics with anti-inflammatory and anti-cancer activities from Salvia miltiorrhiza Bunge (Danshen). Sci. Rep. 2016, 6, 33720. [CrossRef]

7. Fu, L.; Han, B.; Zhou, Y.; Ren, J.; Cao, W.; Patel, G.; Kai, G.; Zhang, J. The Anticancer Properties of Tanshinones and the Pharmacological Effects of Their Active Ingredients. Front. Pharmacol. 2020, 11, 193. [CrossRef]

8. Chang, C.-C.; Chu, C.-F.; Wang, C.-N.; Wu, H.-T.; Bi, K.-W.; Pang, J.-H.S.; Huang, S.-T. The anti-atherosclerotic effect of tanshinone IIA is associated with the inhibition of TNF- $\alpha$-induced VCAM-1, ICAM-1 and CX3CL1 expression. Phytomedicine 2014, 21, 207-216. [CrossRef] [PubMed]

9. Li, H.; Gao, C.; Liu, C.; Liu, L.; Zhuang, J.; Yang, J.; Zhou, C.; Feng, F.; Sun, C.; Wu, J. A review of the biological activity and pharmacology of cryptotanshinone, an important active constituent in Danshen. Biomed. Pharmacother. 2021, 137, 111332. [CrossRef]

10. Slameňová, D.; Mašterová, I.; Lábaj, J.; Horváthová, E.; Kubala, P.; Jakubikova, J.; Wsolova, L. Cytotoxic and DNA-Damaging Effects of Diterpenoid Quinones from the Roots of Salvia officinalis L. on Colonic and Hepatic Human Cells Cultured in vitro. Basic Clin. Pharmacol. Toxicol. 2004, 94, 282-290. [CrossRef]

11. Li, Z.; Zou, J.; Cao, D.; Ma, X. Pharmacological basis of tanshinone and new insights into tanshinone as a multitarget natural product for multifaceted diseases. Biomed. Pharmacother. 2020, 130, 110599. [CrossRef] [PubMed]

12. Fischedick, J.T.; Standiford, M.; Johnson, D.A.; Johnson, J.A. Structure activity relationship of phenolic diterpenes from Salvia officinalis as activators of the nuclear factor E2-related factor 2 pathway. Bioorg. Med. Chem. 2013, 21, 2618-2622. [CrossRef] [PubMed]

13. Ansari, M.A.; Khan, F.B.; Safdari, H.A.; Almatroudi, A.; Alzohairy, M.A.; Safdari, M.; Amirizadeh, M.; Rehman, S.; Equbal, M.J.; Hoque, M. Prospective therapeutic potential of Tanshinone IIA: An updated overview. Pharmacol. Res. 2021, $164,105364$. [CrossRef] [PubMed]

14. Ashrafizadeh, M.; Zarrabi, A.; Orouei, S.; Saberifar, S.; Salami, S.; Hushmandi, K.; Najafi, M. Recent advances and future directions in anti-tumor activity of cryptotanshinone: A mechanistic review. Phytother. Res. 2021, 35, 155-179. [CrossRef]

15. Chiu, T.-L.; Su, C.C. Tanshinone IIA increases protein expression levels of PERK, ATF6, IRE1 $\alpha$, CHOP, caspase-3 and caspase-12 in pancreatic cancer BxPC-3 cell-derived xenograft tumors. Mol. Med. Rep. 2017, 15, 3259-3263. [CrossRef]

16. Chen, Z.; Zhu, R.; Zheng, J.; Chen, C.; Huang, C.; Ma, J.; Xu, C.; Zhai, W.; Zheng, J. Cryptotanshinone inhibits proliferation yet induces apoptosis by suppressing STAT3 signals in renal cell carcinoma. Oncotarget 2017, 8, 50023-50033. [CrossRef]

17. Wang, Y.; Lu, H.-L.; Liu, Y.-D.; Yang, L.-Y.; Jiang, Q.-K.; Zhu, X.-J.; Fan, H.-N.; Qian, Y. Cryptotanshinone sensitizes antitumor effect of paclitaxel on tongue squamous cell carcinoma growth by inhibiting the JAK/STAT3 signaling pathway. Biomed. Pharmacother. 2017, 95, 1388-1396. [CrossRef]

18. Li, X.; Li, Z.; Li, X.; Liu, B.; Liu, Z. Mechanisms of Tanshinone II a inhibits malignant melanoma development through blocking autophagy signal transduction in A375 cell. BMC Cancer 2017, 17, 357. [CrossRef]

19. Chen, L.; Zheng, S.-Z.; Sun, Z.-G.; Wang, A.-Y.; Huang, C.-H.; Punchard, N.A.; Huang, S.-L.; Gao, X.; Lu, Y. Cryptotanshinone has diverse effects on cell cycle events in melanoma cell lines with different metastatic capacity. Cancer Chemother. Pharmacol. 2011, 68, 17-27. [CrossRef]

20. Ye, T.; Zhu, S.; Zhu, Y.; Feng, Q.; He, B.; Xiong, Y.; Zhao, L.; Zhang, Y.; Yu, L.; Yang, L. Cryptotanshinone induces melanoma cancer cells apoptosis via ROS-mitochondrial apoptotic pathway and impairs cell migration and invasion. Biomed. Pharmacother. 2016, 82, 319-326, Erratum in Biomed. Pharmacother. 2019, 120, 109510. [CrossRef]

21. Saraf, R.S.; Datta, A.; Sima, C.; Hua, J.; Lopes, R.; Bittner, M. An in-silico study examining the induction of apoptosis by Cryptotanshinone in metastatic melanoma cell lines. BMC Cancer 2018, 18, 855. [CrossRef]

22. Ueda, Y.; Richmond, A. NF-kappaB activation in melanoma. Pigment Cell Res. 2006, 19, 112-124. [CrossRef]

23. Niu, G.; Bowman, T.; Huang, M.; Shivers, S.; Reintgen, D.; Daud, A.; Chang, A.; Kraker, A.; Jove, R.; Yu, H. Roles of activated Src and Stat3 signaling in melanoma tumor cell growth. Oncogene 2002, 21, 7001-7010. [CrossRef]

24. Masullo, M.; Montoro, P.; Autore, G.; Marzocco, S.; Pizza, C.; Piacente, S. Quali-quantitative determination of triterpenic acids of Ziziphus jujuba fruits and evaluation of their capability to interfere in macrophages activation inhibiting NO release and iNOS expression. Food Res. Int. 2015, 77, 109-117. [CrossRef]

25. Lin, X.; Qureshi, M.Z.; Romero, M.A.; Khalid, S.; Aras, A.; Ozbey, U.; Farooqi, A.A. Regulation of signaling pathways by tanshinones in different cancers. Cell. Mol. Biol. 2017, 63, 53-58. [CrossRef] 
26. Roskoski, R. Cyclin-dependent protein serine/threonine kinase inhibitors as anticancer drugs. Pharmacol. Res. 2019, 139, 471-488. [CrossRef]

27. Starostina, N.G.; Kipreos, E.T. Multiple degradation pathways regulate versatile CIP/KIP CDK inhibitors. Trends Cell Biol. 2012, 22, 33-41. [CrossRef] [PubMed]

28. Al Bitar, S.; Gali-Muhtasib, H. The Role of the Cyclin Dependent Kinase Inhibitor p21cip1/waf1 in Targeting Cancer: Molecular Mechanisms and Novel Therapeutics. Cancers 2019, 11, 1475. [CrossRef] [PubMed]

29. Logotheti, S.; Pützer, B.M. STAT3 and STAT5 Targeting for Simultaneous Management of Melanoma and Autoimmune Diseases. Cancers 2019, 11, 1448. [CrossRef]

30. Tesoriere, A.; Dinarello, A.; Argenton, F. The Roles of Post-Translational Modifications in STAT3 Biological Activities and Functions. Biomedicines 2021, 9, 956. [CrossRef] [PubMed]

31. Decker, T.; Kovarik, P. Serine phosphorylation of STATs. Oncogene 2000, 19, 2628-2637. [CrossRef] [PubMed]

32. Sakaguchi, M.; Oka, M.; Iwasaki, T.; Fukami, Y.; Nishigori, C. Role and Regulation of STAT3 Phosphorylation at Ser727 in Melanocytes and Melanoma Cells. J. Investig. Dermatol. 2012, 132, 1877-1885. [CrossRef] [PubMed]

33. Huang, Y.-C.; Pan, M.; Liu, N.; Xiao, J.-G.; Chen, H.-Q. Effects of nuclear factor-KB and ERK signaling transduction pathway inhibitors on human melanoma cell proliferation in vitro. Oncol. Lett. 2015, 10, 3233-3237. [CrossRef] [PubMed]

34. Kozlova, N.I.; Morozevich, G.E.; Ushakova, N.A.; Berman, A.E. Implication of Integrin $\alpha 2 \beta 1$ in Proliferation and Invasion of Human Breast Carcinoma and Melanoma Cells: Noncanonical Function of Akt Protein Kinase. Biochemistry 2018, 83, 738-745. [CrossRef]

35. Frankowski, H.; Gu, Y.-H.; Heo, J.H.; Milner, R.; del Zoppo, G.J. Use of Gel Zymography to Examine Matrix Metalloproteinase (Gelatinase) Expression in Brain Tissue or in Primary Glial Cultures. In Astrocytes; Milner, R., Ed.; Methods in Molecular Biology; Humana Press: Totowa, NJ, USA, 2012; Volume 814, pp. 221-233. ISBN 978-1-61779-451-3. [CrossRef]

36. Ginda, H.; Kusumi, T.; Ishitsuka, M.O.; Kakisawa, H.; Weijie, Z.; Jun, C.; Tian, G.Y. Salviolone, a cytotoxic bisnorditerpene with a benzotropolone chromophore from a chinese drug dan-shen (salvia miltiorrhiza). Tetrahedron Lett. 1988, 29, 4603-4606. [CrossRef]

37. Lin, H.-Y.; Lin, T.-S.; Chien, H.-J.; Juang, Y.-M.; Chen, C.-J.; Wang, C.-S.; Lai, C.-C. A rapid, simple, and high-throughput UPLC-MS/MS method for simultaneous determination of bioactive constituents in Salvia miltiorrhiza with positive/negative ionization switching. J. Pharm. Biomed. Anal. 2018, 161, 94-100. [CrossRef]

38. Liu, D.; Liu, X.; Xing, M. Activities of multiple cancer-related pathways are associated withBRAFmutation and predict the resistance to BRAF/MEK inhibitors in melanoma cells. Cell Cycle 2014, 13, 208-219. [CrossRef]

39. Kaoud, T.S.; Mohassab, A.M.; Hassan, H.A.; Yan, C.; Van Ravenstein, S.X.; Abdelhamid, D.; Dalby, K.N.; Abdel-Aziz, M. NO-releasing STAT3 inhibitors suppress BRAF-mutant melanoma growth. Eur. J. Med. Chem. 2020, 186, 111885. [CrossRef] [PubMed]

40. Liu, S.; Yamauchi, H. p27-Associated G1 arrest induced by hinokitiol in human malignant melanoma cells is mediated via down-regulation of pRb, Skp2 ubiquitin ligase, and impairment of Cdk2 function. Cancer Lett. 2009, 286, 240-249. [CrossRef]

41. Park, I.-J.; Yang, W.K.; Nam, S.-H.; Hong, J.; Yang, K.R.; Kim, J.; Kim, S.S.; Choe, W.; Kang, I.; Ha, J. Cryptotanshinone induces G1 cell cycle arrest and autophagic cell death by activating the AMP-activated protein kinase signal pathway in HepG2 hepatoma. Apoptosis 2014, 19, 615-628. [CrossRef] [PubMed]

42. Zhang, Y.; Li, G.; Ji, C. Inhibition of human cervical cancer cell growth by Salviolone is mediated via autophagy induction, cell migration and cell invasion suppression, G2/M cell cycle arrest and downregulation of Nf-kB/m-TOR/PI3K/AKT pathway. JBUON 2018, 23, 1739-1744.

43. Liu, C.; Sun, H.-N.; Luo, Y.-H.; Piao, X.-J.; Wu, D.-D.; Meng, L.-Q.; Wang, Y.; Zhang, Y.; Wang, J.-R.; Wang, H.; et al. Cryptotanshinone induces ROS-mediated apoptosis in human gastric cancer cells. Oncotarget 2017, 8, 115398-115412. [CrossRef]

44. Ehexige, E.; Bao, M.; Bazarjav, P.; Yu, X.; Xiao, H.; Han, S.; Baigude, H. Silencing of STAT3 via Peptidomimetic LNP-Mediated Systemic Delivery of RNAi Downregulates PD-L1 and Inhibits Melanoma Growth. Biomolecules 2020, 10, 285. [CrossRef] [PubMed]

45. Mohassab, A.M.; Hassan, H.A.; Abdelhamid, D.; Abdel-Aziz, M. STAT3 transcription factor as target for anti-cancer therapy. Pharmacol. Rep. 2020, 72, 1101-1124. [CrossRef]

46. Momtaz, S.; Niaz, K.; Maqbool, F.; Abdollahi, M.; Rastrelli, L.; Nabavi, S.M. STAT3 targeting by polyphenols: Novel therapeutic strategy for melanoma. BioFactors 2017, 43, 347-370. [CrossRef] [PubMed]

47. Aggarwal, B.B.; Kunnumakkara, A.B.; Harikumar, K.B.; Gupta, S.R.; Tharakan, S.T.; Koca, C.; Dey, S.; Sung, B. Signal Transducer and Activator of Transcription-3, Inflammation, and Cancer: How Intimate Is the Relationship? Ann. N. Y. Acad. Sci. 2009, 1171, 59-76. [CrossRef] [PubMed]

48. Chung, J.; Uchida, E.; Grammer, T.C.; Blenis, J. STAT3 serine phosphorylation by ERK-dependent and -independent pathways negatively modulates its tyrosine phosphorylation. Mol. Cell. Biol. 1997, 17, 6508-6516. [CrossRef]

49. Venkatasubbarao, K.; Choudary, A.; Freeman, J.W. Farnesyl Transferase Inhibitor (R115777)-Induced Inhibition of STAT3(Tyr705)Phosphorylation in Human Pancreatic Cancer Cell Lines Require Extracellular Signal-Regulated Kinases. Cancer Res. 2005, 65, 2861-2871. [CrossRef]

50. Krasil'Nikov, M.; Ivanov, V.N.; Dong, J.; Ronai, Z. ERK and PI3K negatively regulate STAT-transcriptional activities in human melanoma cells: Implications towards sensitization to apoptosis. Oncogene 2003, 22, 4092-4101. [CrossRef] 
51. Vultur, A.; Villanueva, J.A.; Krepler, C.; Rajan, G.; Chen, Q.; Xiao, M.; Li, L.; Gimotty, P.A.; Wilson, M.; Hayden, J.; et al. MEK inhibition affects STAT3 signaling and invasion in human melanoma cell lines. Oncogene 2014, 33, 1850-1861. [CrossRef]

52. Subbiah, V.; Baik, C.; Kirkwood, J.M. Clinical Development of BRAF plus MEK Inhibitor Combinations. Trends Cancer 2020, 6 , 797-810. [CrossRef]

53. Haugh, A.M.; Salama, A.K.S.; Johnson, D.B. Advanced Melanoma: Resistance Mechanisms to Current Therapies. Hematol. Oncol. Clin. North Am. 2021, 35, 111-128. [CrossRef] [PubMed]

54. Tsukada, Y.-I.; Miyazawa, K.; Kitamura, N. High Intensity ERK Signal Mediates Hepatocyte Growth Factor-induced Proliferation Inhibition of the Human Hepatocellular Carcinoma Cell Line HepG2. J. Biol. Chem. 2001, 276, 40968-40976. [CrossRef] [PubMed]

55. Franken, N.A.P.; Rodermond, H.M.; Stap, J.; Haveman, J.; Van Bree, C. Clonogenic assay of cells in vitro. Nat. Protoc. 2006, 1, 2315-2319. [CrossRef] [PubMed]

56. Gupta, A.; Kaur, C.D.; Jangdey, M.; Saraf, S. Matrix metalloproteinase enzymes and their naturally derived inhibitors: Novel targets in photocarcinoma therapy. Ageing Res. Rev. 2014, 13, 65-74. [CrossRef] [PubMed]

57. Kortylewski, M.; Jove, R.; Yu, H. Targeting STAT3 affects melanoma on multiple fronts. Cancer Metastasis Rev. $2005,24,315-327$. [CrossRef] [PubMed]

58. Cerulli, A.; Napolitano, A.; Hošek, J.; Masullo, M.; Pizza, C.; Piacente, S. Antioxidant and In Vitro Preliminary Anti-Inflammatory Activity of Castanea sativa (Italian Cultivar "Marrone di Roccadaspide" PGI) Burs, Leaves and Chestnuts Extracts and their Metabolite Profiles by LC-ESI/LTQOrbitrap/MS/MS. Antioxidants 2021, 10, 278. [CrossRef]

59. Raineri, A.; Fasoli, S.; Campagnari, R.; Gotte, G.; Menegazzi, M. Onconase Restores Cytotoxicity in Dabrafenib-Resistant A375 Human Melanoma Cells and Affects Cell Migration, Invasion and Colony Formation Capability. Int. J. Mol. Sci. 2019, 20, 5980. [CrossRef] 